\title{
The Effect of Beam Curvature on Bending Properties of Sandwich Structures
}

\author{
Ladislav Fojtl ${ }^{1,2}$, Sona Rusnakova ${ }^{1}$, Milan Zaludek ${ }^{1}$, Vladimir Rusnak ${ }^{3}$ \\ ${ }^{1}$ Department of Production Engineering, Faculty of Technology, Tomas Bata University in Zlín. Vavrečkova 275,76001 \\ Zlín.Czech Republic.E-mail: fojtl@ft.utb.cz, rusnakova@ft.utb.cz, zaludek@ft.utb.cz \\ ${ }^{2}$ Centre of Polymer Systems, Tomas Bata University in Zlín, Trida Tomase Bati 5678, 76001 Zlín, Czech Republic \\ ${ }^{3}$ Faculty of Metallurgy and Materials Engineering, VŠB-Technical University of Ostrava, 17. listopadu 15,70833 \\ Ostrava-Poruba, Czech Republic. E-mail: vladimir.rusnak@form-composites.com
}

Sandwich composites are well known for many years and its place among the construction materials have they deserved mainly due to very good mechanical properties related to their weight. These materials have been a subject for many researches, but very few of them were focused on the behavior of curved constructions in bend with respect to their specific shape (curvature). With increasing number of new materials and resulting possible material combinations, it is necessary to characterize performance of new prepared structures and also evaluate the effect of a shape on the behavior of sandwich constructions with regard to their material composition. Presented paper deals with an investigation of flat and curved beams of sandwich structures, which correspond by their material composition to those, used in transport industry. Specifically, the influence of curvature size on a change of bending properties of structures with specific material composition compared to flat constructions is evaluated. This influence is also investigated in terms of specimen clamping and type of bending test. Obtained results showed that properties of sandwich structures are dependent not only on size of curvature, bud also on core thickness. Moreover, these results can help designers, constructers or technologists with design, dimensioning or production of these materials for specific applications.

Keywords: Sandwich structure, Beam, Curvature, Shape, Bending, Load capacity, Core, Prepreg

\section{Acknowledgement}

The authors gratefully acknowledge the financial support of this research by the internal grant of Tomas Bata University in Zlín No. Zlín No. IGA/FT/2016/002 funded from the resources of specific university research.

\section{References}

[1] ZENKERT, D. (1997). Nordic Industrial Fund, The Handbook of Sandwich Construction, p. 447. EMAS Publishing, Worcestershire.

[2] CAMPBELL, F. (2010). Structural Composite Materials, p. 612. ASM International, Ohio.

[3] LEHMHUS D., BUSSE M., HERRMANN A., KAYVANTASH K. (2013). Structural Materials and Processes in Transportation, p. 598. Wiley-VCH Verlag GmbH, New York.

[4] SUBA, O., SYKOROVA, L., LUKOVICS, I. (2012). Stress analysis of injection - moulded cylindrical parts reinforced with short fibres. In: Manufacturing technology. Vol 12, No. 13, pp. $251-254$.

[5] TOFT, G. (1983). Stresses in a curved laminated beam. In: Fibre Science and Technology, Vol. 19, Issue 4, pp. $243-267$.

[6] BABA, B.O., THOPPUL, S. (2009). Experimental evaluation of the vibration behavior of flat and curved sandwich composite beams with face/core debond. In: Composite Structures, Vol. 91, pp. 110-119.

[7] SMIDT, S. (1995). Bending of curved sandwich beams. In: Composite Structures. Vol. 33, pp. 211-225.

[8] SMIDT, S. (1999). Bending of curved sandwich beams, a numerical approach. In: Composite Structures. Vol. 34, pp. 279-290.

[9] RUSNAKOVA, S., FOJTL, L., ZALUDEK, M., RUSNAK, V. (2014) Design of material composition and technology verification for composite front end cabs. In: Manufacturing Technology, Vol. 14, Issue 4, pp. 607-611.

[10]GIBSON L. J., ASHBY M. F. (1999). Cellular solids: structure and properties, p. 510. Cambridge University Press, Cambridge.

[11]Core materials, NetComposites. [online]. 2015 [cit. 2015-10-17]. Available at: <http://www.netcomposites.com/guide/core-materials/>

[12]Prepregs, Technical brochure. Gurit. [online]. 2015 [cit. 2015-10-03]. Available at: <http://www.gurit.com/files/documents/prepreg-brochurev3pdf.pdf>

[13]KAPPEL, E. (2015) Spring-in of curved CFRP/foam-core sandwich structures, In: Composite Structures. Vol. 128, pp. $155-164$. 